- ENTREVISTA INTERVIEW 


\section{FALA SOBRE GOVERNANÇA CORPORATIVA: o caso de sucesso do Grupo Pão de Açúcar}

Abilio dos Santos Diniz, 67, nasceu na cidade de São Paulo, onde também realizou seus estudos. Formou-se em Administração de Empresas, em 1959, pela Fundação Getulio Vargas, e, em seguida, estagiou e pós-graduou-se em Administração e Economia nos Estados Unidos da América (EUA). Sua carreira profissional, iniciada em 1956, foi inteiramente dedicada ao Grupo Pão de Açúcar, fundado em 1948. Assumiu as atividades como Gerente de Vendas até chegar à posição que ocupa hoje: Presidente do Conselho de Administração. Dividiu com seu pai, o Comendador Valentim dos Santos Diniz, a responsabilidade pela criação e desenvolvimento de um grupo empresarial voltado para distribuição de alimentos. No início da década de 90 , tornou-se acionista majoritário do Grupo Pão de Açúcar, então à beira da ruína, e foi o responsável pela grande virada que resultou, hoje, na constituição da maior rede de varejo do país, com cerca de 600 lojas espalhadas por 12 Estados e mais de 70 mil colaboradores. Como presidente-executivo do Grupo, promoveu as políticas de governança corporativa da empresa no fim de 2002, quando passou a Presidente do Conselho de Administração. Participou também de entidades de classe e de muitos conselhos consultivos e de administração. Durante dez anos, de 1979 a 1989, esteve no centro do cenário político do país como membro do Conselho Monetário Nacional, época em que coordenou, ao lado de Mário Henrique Simonsen, Yoshiaki Nakano, Paulo Rabelo de Castro, Edmar Bacha e Luiz Carlos Bresser Pereira, a publicação do livro Reforma econômica para o Brasil - anos 90. Além de empresário, tornou-se conhecido como atleta e grande incentivador das atividades esportivas como fator de melhoria da qualidade de vida. Abilio Diniz é autor do best-seller Caminhos e escolha - o equilibrio para uma vida mais feliz. 
Abilio Diniz talks about corporative governance: the case of Grupo Pão de Açúcar success 
São Paulo: Uninove, Campus Vila Maria, 28 de outubro de 2004.

\section{1a Parte - trechos da palestra}

Abilio Diniz (AD): Sou considerado um homem de sucesso, mas, se sou ou não, isso às vezes pouco importa; o que importa é que as pessoas me vêem assim, como homem de sucesso. $O$ importante, penso, é nunca se esquecerem de que, como alunos de Administração e Marketing, a primeira coisa a observar é que é preciso estar atento a isto: existe o fato e a versão do fatoe, normalmente, quando a versão do fato não corresponde à verdade, a mentira não se sustenta por muito tempo. Durante a vida vocês terão sempre de conviver com isso, principalmente aqueles que vão dedicar-se à carreira de marketing, convencer as pessoas, comunicar e transmitir mensagens. Vocês têm que se lembrar sempre disto: existe o fato e a versão do fato. De qualquer forma, já que sou pelo menos considerado um cara que deu certo, que tem sucesso, a primeira coisa que vocês poderiam perguntar é: "Quais são as receitas para o sucesso?" Infelizmente talvez venha a frustrá-los - não tenho a receita. Inclusive, lá em nossa companhia, temos o hábito de colecionar frases e colocá-las em todas as paredes. No auditório temos algumas afixadas e uma delas, bem visível e de que gostamos muito, diz: "Uns sonham com o sucesso; nós acordamos cedo e trabalhamos duramente para atingi-lo." Esta tem sido a realidade da minha vida: se eu alcancei sucesso foi com muito esforço e dedicação. O próprio negócio que abracei, a escolha que fiz - trabalhar no campo de distribuição - transformou-se num empreendimento de grande porte. Hoje nossa empresa tem quase 600 lojas, emprega 70 mil pessoas, movimenta cerca de 22 mil toneladas de mercadoria por dia (o equivalente a 1200 carretas) e vai vender este ano mais de 15 bilhões de reais - é uma das maiores do país. Agora, para conseguir tudo isto, não basta apenas inspiração, mas também muita transpiração, isto é, muito esforço e dedicação, aí está a chave do sucesso. Tudo isso para transmitir a vocês o seguinte: a vida não é fácil, a gente tem que lutar muito, e essa luta nos traz a recompensa. Agora, o importante é sentirmos que, embora não seja fácil, a vida pode ser muito bonita se soubermos olhá-la com amor, com dedicação, buscando sempre o caminho da felicidade. Vou contar para vocês um pouquinho da minha história e espero que, com isso, possa passar algumas coisas para vocês. No entanto, não gostaria de ficar o tempo todo falando; gostaria que o microfone circulasse e que vocês também falassem comigo, que me perguntassem coisas, expressassem suas idéias, pois acredito que o diálogo enriqueça nossa conversa e fico mais feliz com isso. Ora, acho que a coisa mais forte que tenho dentro de mim é a minha fé. Fui introduzido na religião por meu pai e minha mãe, mas não sei bem por que, depois de os meus irmãos nascerem somos seis e, entre mim e o segundo, há uma diferença de mais de sete anos -, meus pais deixaram de ir à igreja. Lembro-me de que, quando pequeno, morava na Avenida Brigadeiro Luiz Antônio e subia aquela avenida toda para ir sozinho à missa na Imaculada Conceição. Não sei o porquê disso, não tenho explicação, só digo a vocês que uns acreditam e valorizam, outros não. Para mim, a maior força é a fé, e eu a tenho; agradeço a Deus o fato de me ter feito forte e saudável, com algumas características que julgo de suma importância em minha vida: determinação e muita disciplina, o que me ajudou a superar toda sorte de dificuldades. Convém, neste momento, fazer alguns recortes. Eu era pré-adolescente, por volta de meus 10 anos, baixinho, gordinho, redondinho e me sentia totalmente fragilizado, inferiorizado. À época, meu pai 
tinha uma padaria na Liberdade, ali no alto da Vargem do Glicério, que hoje está muito diferente. Para facilitar as coisas, quando saí do primário, ele me colocou no Colégio Anglo Latino (que já desapareceu, mas que deu origem ao curso Anglo, que vocês todos conhecem) ali mesmo na Vargem do Glicério, onde passei a conviver com uma classe social bem baixa, com meninos muito agressivos, acostumados à rua, a uma vida mais rude; e eu, filho único até os 7 anos, de repente caí naquela selva, o que tornou os primeiros tempos de minha vida naquele colégio extremamente difíceis, pois parece que a diversão da turma consistia em, pela manhã, bater no amigo; à tarde, bater no amigo e à noite, para variar, bater no amigo - o baixinho e gordinho, para eles, era uma festa. No entanto, como diz o ditado, não há mal que sempre dure nem bem que nunca se acabe. Um dia as coisas começaram a se modificar um pouco e fui me transformando. Precisava dar a volta por cima, acabar com aquele bate/apanha em que só eu levava a pior. É bom lembrar que, naquele período, as coisas eram mais difíceis, meu pai era muito duro comigo e dizia: homem não chora. Por isso, nem chorar podia, mesmo chegando machucado todo dia em casa. Eu saía do colégio, pegava o bonde, passava pelo centro da cidade, pela Rua Quintino Bocaiúva e ia a vários lugares que talvez não mais existam, lugares que o Ricardo (Galuppo), que me ajudou a escrever o livro, conheceu e investigou. Naquela rua havia um prédio que tinha duas academias, uma era a academia Ono de judô, caratê, e a outra a academia de boxe dos Zumbano.
Passei por ali um dia, vi aquele negócio e disse: "Puxa! é aqui mesmo que eu vou ficar." Lá entrei e comecei a praticar um esporte realmente voltado para defesa (que, às vezes, é agressão), mas um esporte que, àquela altura, para mim parecia de sobrevivência. Realmente, a atividade transformou meu convívio com os meninos da escola: eu, que apanhava todo dia, passei a bater. $O$ fato é que esse episódio trouxe duas coisas importantes para mim, uma positiva e outra negativa: de um lado, o convívio mais direto com o esporte me permitiu perceber as possibilidades do trabalho físico, isto é, quanto você podia modificar seu corpo, quanto podia ficar forte, quanto podia crescer; de outro, uma agressividade totalmente indevida, indesejada, além da arrogância e prepotência que me acompanharam por boa parte da minha vida, das quais só consegui me libertar depois de muitos e muitos anos. Foi um período realmente muito importante, mas afirmo que nunca fui 'do mal', sempre fui uma pessoa do bem, até, felizmente, pela formação baseada na fé. Vamos avançar mais um pouco: uma coisa que sempre foi muito importante para mim e que fez com que as coisas dessem certo foi a capacidade de tomar decisões corretas no momento adequado. A primeira decisão, talvez a mais importante, foi ter feito Administração na Fundação Getúlio Vargas, como vocês que estão fazendo agora na UNINOVE. Fui aluno da segunda turma da Escola de Administração de Empresas aqui em São Paulo, no tempo que ela não ficava na Av. Nove de Julho, onde é hoje, mas na Rua Martins Fontes, no centro da cidade, no antigo 
prédio da Delegacia Regional do Trabalho. Naquele tempo, a técnica do business administration criada pelos norte-americanos era uma coisa nova no país e até em desenvolvimento no mundo. Os professores da GV vinham da Michigan States University e os professores brasileiros iam para lá aprender os métodos administrativos, isso no fim do anos 50 . Tudo era muito novo naquele tempo e realmente me encantei com o que estava aprendendo na escola com os professores. Havia um que tinha sido piloto de caça durante a Segunda Guerra Mundial, eu achava aquilo a coisa mais linda do mundo, o cara estava ali me ensinando. Já que não tinha muita coisa para fazer aqui - havia poucas possibilidades de emprego no país naquele tempo -, decidi reunir o dinheirinho que tinha e ir para Michigan fazer MBA, doutorado, queria ser professor, tinha direcionado minha vida para essa carreira. Eu estava com tudo, estava com a apllication (inscrição) na Michigan University. À época, meu pai tinha uma doceira, na qual, aliás, eu trabalhava - coisa que me dava algum dinheiro para viver modestamente, mas nenhuma satisfação. Então, ele me chamou e disse: olha, estou com idéia de montar um supermercado numa loja que fiz (ele tinha construído um predinho na Brigadeiro Luiz Antônio). Embora não soubesse exatamente do que ele estava falando, fui investigar o que era aquela história de supermercado. Naquele tempo, existiam dez lojas de supermercados na cidade de São Paulo, oito pertencentes a uma rede chamada Peg-Pag e mais duas pertencentes ao Sirva-se. Fui olhar aquilo, passei a observar como se fazia a distribuição de produtos na cidade de São Paulo e descobri que ali estava uma grande oportunidade de fazer alguma coisa diferente e, principalmente, melhor do que estava sendo feito. Esqueci os meus estudos e procurei conhecer detalhes do negócio que viria abraçar com determinação e no qual estou até hoje. Foi a grande decisão de minha vida, pois fiquei e deu certo, mas sem abandonar a idéia de ser professor e desenvolver meu lado acadêmico, o que não cheguei a concretizar, envolvido que estava com minhas atividades de administrador. Voltei aos EUA, em 1965, e fiz um curso de marketing que me foi extremamente importante; em seguida, estudei economia na Columbia University para matar, pelo menos, aquele gostinho de fazer aquilo que a princípio desejara, e também saborear a oportunidade de continuar os meus estudos. As noções de marketing adquiridas no curso instigaram-me a dinamizar meu trabalho e buscar coisas novas e modernas para levar avante meu empreendimento. Fui para a Europa e para os EUA ver o que estava sendo feito em países mais desenvolvidos; procurei trazer as melhores técnicas de gestão para cá e desenvolvê-las ainda mais aqui no país - a coisa deu certo. Isso foi em 1959; basta lembrar que, no fim desse ano, abrimos a primeira loja e, dez anos depois, tínhamos mais de 50. Nessa época, meu pai recebeu um convite do governo português para abrir lojas em Portugal e, como muitas coisas na minha vida aconteceram assim, ele me chamou e perguntou o que eu achava. Disse-lhe que iria a Portugal para sondar o mercado. Lá chegando, verifiquei que o país estava na idade da pedra em matéria de distribuição e que poderíamos revolucionar o mercado se levássemos para lá nossa experiência, que era nosso diferencial. Aceitamos o desafio e, em poucos anos, conseguimos desenvolver uma grande companhia lá, claro que não tão grande quanto a nossa rede no Brasil. Mais uma vez decidi 
aproveitar a oportunidade, mas como nem tudo sai conforme planejado, cinco anos depois, em 1974, ocorreu em Portugal a Revolução dos Cravos. Em conseqüência, nossa companhia foi estatizada e entregue às comissões de trabalhadores. Contrariando voz corrente na família, que nos aconselhava a abandonar tudo, decidi que deveria continuar lutando pelo investimento feito, ou seja, recuperar a companhia, o que foi conseguido três anos depois com a mudança política no país, que passou a ter um regime socialista no estilo da socialdemocracia européia. Essa decisão foi de fundamental importância, pois mais tarde, em 1992, graças à companhia em Portugal, conseguimos sair da crise em que mergulháramos em 1989/1990. Convém traçar aqui o histórico da crise para que vocês compreendam o processo. No fim dos anos 70, meus irmãos começaram a chegar

à companhia e, como era uma empresa familiar, apesar de eu ter feito todo o trabalho, meu pai foi repartindo o empreendimento em 'capitanias hereditárias', dando a cada filho seu quinhão. Com isso, instaurou-se ali uma grande confusão administrativa, o que para mim foi um choque. Eu que, durante anos, mantivera a companhia como uma empresa de ponta, com profissionais de grande competência, de repente via todo o poder e hierarquia contestados, porque em matéria de poder, em matéria de administração, as regras são muito simples: manda quem pode, obedece quem tem juízo. Mas no meu caso isso não era possível, pois eu não tinha poder suficiente, pulverizado com a entrada de meus irmãos e a divisão feita; aliás, ninguém dispunha de poder suficiente para manter a hierarquia e a estabilidade da empresa. Como não conseguia dar seqüência ao meu projeto, aceitei o convite para assumir um cargo no Conselho Monetário Nacional, que me fora feito, à época, pelo ministro da Fazenda Mário Henrique Simonsen. Assumi e passei a dedicar boa parte de meu tempo às atividades em Brasília, deixando de me preocupar com o Pão de Açúcar. Passaram-se dez anos. Em 1989, meu pai me chamou novamente e me pediu que fizesse alguma coisa pela companhia, pois ela estava dando demonstrações claras de fragilidade. Acolhi o pedido e retornei. Assumi a direção da empresa e tentei fazer um programa de reestruturação e reerguimento, mas não deu tempo porque, logo em 90 , veio o governo Collor com o seqüestro da poupança $e$ uma série de medidas de grande impacto, instaurando uma enorme recessão no país. O Pão de Açúcar, frágil como estava em decorrência de uma situação conjuntural totalmente adversa, não resistiu e quase desapareceu. Posso dizer que esse foi o período mais difícil de minha vida, pois nele ocorreram os três grandes episódios traumáticos: a quase quebra da empresa, o conflito familiar e o seqüestro. Fui seqüestrado em dezembro de 1989, época em que havia uma onda de seqüestros e os Diniz eram vistos como membros de uma família com muito dinheiro, pois as lojas vendiam muito, movimentavam grandes somas. Eu sabia disso, sabia do risco que corríamos e, por isso, pus segurança para minha família. E para mim? Imagine! Um homem forte, briguento, esportista, quem vai se meter com um encrenqueiro como eu, e mais, treinado por israelenses. Atirar eu atiro bem, trazia arma do lado da perna, imagine: arrogante, prepotente como eu era, não me passava pela cabeça que alguém viesse a se meter comigo. As pessoas que me assessoravam na segurança me alertavam, falavam dos pontos 
onde poderia acontecer o seqüestro - e foi exatamente assim. Numa determinada manhã, ao sair com meu carro, encontrei uma ambulância atravessada na rua; pressentindo o seqüestro, procedi da forma como havia sido treinado: cheguei bem perto da ambulância, abri a porta lateral deixandoa como proteção, saquei a arma, apontei para os caras, mas um outro carro veio por trás, bateu no meu e me desconcentrou totalmente. Eles eram profissionais, altamente profissionais. Houve briga de rua, rolamos não sei por quanto tempo, mas acabei seqüestrado, posto num buraco debaixo da terra, completamente sem ar. Eles haviam feito um caixote debaixo da terra, com um buraco em cima, e do lado de fora tinha um ventilador que jogava ar por esse buraco para dentro do caixote, mas era insuficiente, eu tinha que levantar toda hora para respirar, pois ficava tonto com a falta de ar. Era uma situação de enlouquecer e a única coisa em que eu pensava era que iria morrer. É interessante porque, quando você se vê frente a frente com a morte acho que acontece com todas as pessoas -, você faz um balanço da sua vida, começa a olhar o que você é, o que faz, fez e o que deixou de fazer. Foram momentos de muita tensão, principalmente porque eu não sabia de que forma morreria, não sabia se ia enlouquecer, se ia atacar o guarda que entrava uma vez por dia para levar alimento. No começo, não conseguia nem rezar, embora tivesse fé. Entretanto o tempo foi passando e quando senti que começava a fazer contato com Deus, pedi-lhe que não me deixasse perder a fé. Coincidência ou não, ou milagre, só sei que as coisas começaram a melhorar, pois em pouco tempo conseguiram pegar alguns dos seqüestradores, e os que estavam comigo ainda tentaram resistir, usando-me como escudo, mas se renderam.
Quero dizer que todas essas coisas que ocorreram em minha vida me marcaram muito, pois me fizeram aprender bastante. A arrogância e a prepotência, aos poucos, foram dando lugar à humildade. Passei a enxergar a vida de uma forma completamente diferente e descobri que a beleza está do outro lado, está na bondade; a grandeza está na humildade, o bom é saber ouvir, saber compreender, conciliar e não atacar - a beleza está em você realmente poder olhar para o mundo com outros olhos e dizer: "o mundo é bom e, se nós ajudarmos, vai ficar melhor ainda." Desse tempo para frente, tenho cada vez mais perseguido esse caminho, que é lutar pela felicidade, procurar realmente ser feliz e, se possível, ajudar as pessoas a serem felizes; e aí está a razão principal do meu livro, tentando atingir o maior número possível de pessoas. Eu gostaria de contar alguma coisa para vocês que está no livro. Nos 3 capítulos iniciais, falo sobre esporte, alimentação e combate ao estresse. Nos outros três, falo de questões de ordem: autoconhecimento, espiritualidade e fé, a força que eu tenho e que acho que as pessoas podem conseguir acreditando em algo superior. Se pudesse resumir em algumas máximas, seriam as seguintes:

- alimentem-se adequadamente;

- planejem suas atividades;

- estabeleçam prioridades;

- sejam persistentes, determinados;

- respeitem limites, principalmente os do corpo;

- pratiquem esporte;

- amem tudo o que fazem;

- trabalhem com prazer e...

- nunca percam a fé. 


\section{2a Parte - questões do público discente}

Pergunta: O que acha da evolução do Wall Mart no Brasil?
AD: Desde 95 somos uma companhia de capital aberto, capital pulverizado que pode ser do mundo inteiro; temos sócios franceses desde 99, quando abrimos o capital. Para isso, fizemos o que se chama bond show, que é sair pelo mundo - EUA e várias de suas cidades, Europa e seus vários países - conta- tando investidores, contan- do nossa historia e fazendo o lançamento de capital. Os investidores, principal- mente os norte-americanos, olhavam para mim e minha equipe - estamos aí há dez anos, temos respeito, eu os sua vida hoje? conheço e acho que esta é a grande vantagem: conheço os dirigentes, a técnica, aquilo que fazem de bom e o que fazem de mal, o marketing está entrando lá agora... Mesmo assim compraram nossas ações; tínhamos um preço em torno de 12 dólares e fechamos a 10,5 dólares, uma transação muito bem recebida pelo mercado. Procuramos ter disciplina e vontade de aprender sempre, de conhecer o que as pessoas estão fazendo. Eles são uma grande empresa e eu diria que, em relação a nós, o que têm de diferente e maior é o tamanho, pois hoje constituem a maior empresa do mundo em todos o setores. Um grande tamanho e também uma empresa de informação, não exatamente a parte de informática, que eu considero mais sofisticada do que a nossa porque eles, com a facilidade de falar em inglês, podem fazer boa parte do trabalho, além de a tecnologia de informação ter, para eles, custo mais baixo, principalmente na Índia. Assim, ficamos ainda mais espertos, mais atentos e mais humildes do que somos; estamos sempre dispostos a aprender e a estar de olho nos lugares em que possamos buscar coisas novas, diferenciais. E a vida continua, a luta sempre foi assim e nós vamos a ela, está muito bom!

Pergunta: Muitos costumam perguntar sobre o pior momento de sua vida. Eu gostaria de saber do senhor qual o melhor momento de

AD: $O$ pior foi exatamente quando passei pelas brigas de família e o Pão de Açúcar quase quebrou; somado a isso, o seqüestro, tudo praticamente ao mesmo tempo, fim dos anos 80, começo dos 90 - esse foi o pior momento de minha vida. Também foram, digamos assim, momentos da grande descoberta de onde estavam a beleza e a grandeza das coisas. Agora, o melhor momento da minha vida é hoje, primeiro porque é hoje. Não vou dizer que não sinto saudade de algumas coisas que fiz no passado, sinto de alguns campeonatos brasileiros de pólo a cavalo - fantástico o dia que você ganha um campeonato brasileiro! -, das grandes vitórias do esporte, dos grandes momentos que levam à nostalgia, mas quem chega a essa altura da vida como eu, com a felicidade de ter saúde, força, de ter uma companheira que considero ideal, de ter os filhos que tenho, a família que tenho, de ter a possibilidade de chegar e ser recebido por vocês do jeito que fui, eu diria que, certamente, o melhor momento da minha vida é hoje, é hoje à noite.

Pergunta: Em relação à reestruturação que o senhor comandou no Pão de Açúcar, é verdade que um dos principais passos foi o encurtamento da distância entre os cargos de gerência e os de produção, priorizando a opinião dos funcionários para saber quais eram os problemas? 
AD: É verdade, e esse é até um case de administração. Os livros-texto de Administração, vocês devem saber, sugerem que você tenha o menor número de níveis nas hierarquias. $O$ ideal seria ter o vértice da pirâmide encostado na base, ou seja, que não houvesse nenhum nível intermediário entre o presidente de uma empresa e o pessoal de nível mais baixo. Seria o ideal, mas entendo que é utópico, não existe. É ruim ficar criando muitos e diversos níveis: um presidente, um vice, um superintendente, um diretor de não sei o quê, pois você vai transmitindo coisas de um para o outro e leva muito tempo nesse percurso de cima para baixo e de baixo para cima. De fato, a primeira coisa que fiz no início da reestruturação foi cortar o primeiro nível, até porque era uma diretoria que tinha fracassado; então cortei toda a diretoria executiva e passei a trabalhar diretamente com o segundo e terceiro níveis, encurtando a distância. Além disso, criei um mote - corte, concentre e simplifique -, e saímos cortando, cortando e cortando. Tínhamos, naquele momento em que a crise se instaurou, 40 e poucos mil funcionários e reduzimos para 18 mil; estávamos com 400 e poucas lojas e descemos para pouco mais de 200 , cortando, cortando, cortando, quer dizer, tínhamos uma série de atividades paralelas e eliminamos tudo, para nos concentrar naquilo que em inglês se chama core business, ou seja, aquilo que é a nossa atividade principal. Exemplo: tínhamos um banco e cortamos. Sobre o case de reestruturação do Pão de Açúcar já existe muita coisa escrita e foi um trabalho que deu certo, transformou-se num caso de sucesso. E nisso não há mistério nem milagre, nada de excepcional; as coisas que fiz qualquer um poderia fazer, mas acontece que poucos fariam, porque uma das coisas que é duro fazer é cortar. Afinal, fomos de 40 e tantos mil funcionários para 18 mil, de 400 e tantas lojas para 200, e repentinamente cortamos vários níveis. $O$ fato é que instauramos uma outra cultura dentro da companhia. Primeiro, a cultura

da humildade: realmente não achamos que sabemos tudo, estamos sempre dispostos a aprender. Kant tem uma frase que está na cultura da companhia: "Quero ser hoje melhor do que fui ontem e amanhã melhor do que sou hoje." Isso está no vento que corre por dentro da organização, isto é, a obsessão pela melhoria, pelo crescimento, pelo descobrimento de novas coisas e a humildade de aprender $\mathrm{e}$ aprender. Sobre os níveis de que falei, tenho isso até hoje, um programa que faço de 15 em 15 dias, uma quinta-feira sim, uma não, que é o 'Fale com o Abilio'. Num auditório como este da UNINOVE, reunimos quinzenalmente o pessoal daquela área que chamamos de 'chão de loja', sem gerente nem encarregado, apenas o pessoal de baixo. Falam comigo aberta e diretamente, contam suas vidas, seus casos. Muitos programas que desenvolvemos no Pão de Açúcar nasceram desse bate-papo, inclusive projetos ambiciosos que chamamos de sonho. Um dia, num 'Fale com o Abilio' grande, que realizamos anualmente e é um pouco maior que o quinzenal, surgiu alguma coisa que parecia um sonho: as pessoas dizendo como deveriam fazer para ter acesso à realidade da casa própria. Começamos a tratar aquilo de início como programa do sonho e, neste ano, alguns meses atrás, entregamos o primeiro módulo de 300 casas para gente do Pão de Açúcar. Foi um programa feito dentro da companhia, em Itapevi, e já estamos 
saindo com outros módulos. Outros programas surgiram daí, por exemplo, o 'Lugar onde você mora'. Em muitas lojas, principalmente na cidade de São Paulo, o cidadão mora na Zona Leste e trabalha na Zona Sul; dá para você aproximá-lo do lugar onde mora, ou do lugar onde estuda, dos lugares aonde ele tem de ir normalmente. É preciso mesmo o presidente da empresa estar sempre em contato com as pessoas mais 'de baixo', é lá que soam os tambores, é lá que a vida acontece - isso é extremamente importante. Obrigado por pela oportunidade de falar sobre isso.

\section{Pergunta: Focando}

a empresa familiar, onde e quando se pode localizar a essência e a base da sua intuição, do que o levou à profissionalização e à profissionalização de seu grupo? Baseado em que condições e características você percebeu que era hora de profissionalizar e trazer para o grupo uma diretoria executiva, prestigiando apenas as pessoas imbuídas do espírito de distribuição e varejo?

\footnotetext{
AD: Vocês são alunos de Administração com especialização em marketing; por isso, vou-me alongar um pouco nesse tema, porque acho importante vocês entenderem e saberem com clareza aquilo que penso. Não acredito em empresa familiar bem-sucedida depois de um determinado tamanho; isso não quer dizer que a pessoa não possa trabalhar com o pai, que vocês não possam se dar bem durante um determinado tempo, que não possa uma família trabalhar junto. Claro que pode! O que não pode é pôr a empresa a serviço da família ou a família a serviço da empresa; não pode chegar e dizer: "Bom, meus filhos estão crescendo e eu tenho que arrumar lugar para eles dentro da
}

empresa, pois ninguém é de mais confiança do que meus próprios filhos. Vou colocar um aqui, outro ali; não, espera um pouco, também tem meus primos, sobrinhos, meu irmão...". E assim você vai ajeitando a empresa para ser administrada pela família. Não acredito em empresa familiar desse tipo. Para mim, é uma coisa dogmática, o que não quer dizer que não exista exceção, porque se não existisse não se confirmaria a regra. Até vocês nos seus estudos já se devem ter defrontado com pesquisas que apontam empresas familiares algumas vezes com mais sucesso do que as de capital pulverizado. Há algo aqui que não podemos confundir: uma coisa é gestão, management, gerenciamento, cargos executivos. Quando digo que não dá para pôr a empresa a serviço da família, estou me referindo ao preenchimento de cargos executivos com familiares; outra coisa é você ter uma família controlando a empresa, por exemplo, o caso do Wall Mart aqui citado, a maior empresa do mundo. Se perguntássemos se o Wall Mart é uma empresa familiar ou de capital pulverizado, teríamos de responder que é uma empresa familiar porque uma família consegue ter controle suficiente, embora haja enorme pulverização das ações, ou seja, uma família consegue ter um determinado volume de ações que lhe permite eleger o sênior e concentrar a gestão em sua mão, tomando isso como política da empresa e com sucesso. Agora, não pensem que existe algum Wallton no nível executivo da empresa: nada, são empresas totalmente profissionalizadas, com executivos contratados, mas com controle familiar. Veja a CDB-Pão de Açúcar, uma empresa de controle familiar porque eu tenho o controle; apesar de estar pulverizada no mercado e de ter sócios franceses, detenho o controle e elejo o presidente. $\mathrm{O}$ que fiz foi manter a empresa realmente 
independente da família, não do controle acionário e da direção do principal. Ano passado, tomamos a decisão e afastamos todos os Diniz (na verdade eu e minha filha mais velha, Ana Maria) da companhia e da gerência executiva e elegemos o presidente. Afastei-me em março do ano passado e fui para a presidência do conselho de administração, na qual, por sinal, trabalho mais do que antes, mas isso é um detalhe absolutamente secundário. Elegemos um Conselho de Administração que toca a empresa que já existia e aumentamos o número, trabalhamos naquilo que se chama governança corporativa. Elegemos comitês no Conselho de Administração que agora dirige a empresa, temos o Comitê Executivo, responsável por toda a política da empresa, e a Diretoria Executiva, quer dizer, tomamos decisões conscientes, ou seja, formatamos a empresa de modo a caminhar independentemente das pessoas que lá estão. $O$ que vai acontecer se $A, B$ ou $C$ não mais estiverem lá em algum momento, é futuro. Demos à empresa o que consideramos uma vida própria, foi o que fizemos.

Pergunta: O senhor é um dos empresários mais assediados pela mídia. Como lida com esse assédio e a questão de ser considerado um empresário bem-sucedido? Agregando: o senhor já teve experiência em cargo público? Nunca teve vontade de disputar um cargo político na prefeitura de São Paulo, governo do Estado ou quem sabe até na Presidência?

AD: Acho que o termo 'assediado' é um pouco forte. Não posso me revoltar com gente que quer fazer notícia, pois é preciso gerar notícia; não posso recriminar gente que está exercendo sua função. O que recrimino e algumas vezes me irrita é o mau jornalismo. Jornalista é como médico: tem que ter código de ética; se eu tenho de informar, meu dever é informar algo que mereça estar no domínio público. Chegar para você como jornalista e dizer "por favor, não divulgue" não é correto. A mídia precisa divulgar, a não ser que exista uma razão maior como, por exemplo, casos de seqüestro, que pelo menos parte da mídia não divulga, pois isso é trabalho da polícia. Eu convivo com isso e acho que tenho boa relação com a mídia; eles compreendem que não faz parte do meu trabalho ficar dando entrevista todos os dias, mas, de vez em quando, falo com um e depois com outro. Eles entendem que eu não gosto de aparecer demais; convivo muito bem, respeito a mídia e acho que ela me respeita. Agora, cargo público não, não quero; estive dez anos como membro do Conselho Monetário Nacional, me envolvi fortemente na vida pública, fiz de tudo por esse país, negociei dívida, ia a todas as reuniões do Fundo Monetário, procurava defender o Brasil de todas as maneiras. No entanto, depois de dez anos, tive a sensação de que só havia feito inimigos e nenhum amigo; tive a sensação de que saía de lá sem ter conseguido fazer nada, embora tenha havido muita gente a me dizer que tinha feito muita coisa. Eu não acho, entendo que faço muito mais como empresário. Se hoje temos 70 mil pessoas trabalhando conosco, queira Deus que amanhã eu tenha 100 mil e mais, e mais, e mais, pois, gerando postos de trabalho, penso que contribuo, é parte de minha responsabilidade social e minha percepção é de que, assim, faço muito mais do que exercendo qualquer cargo público.

Pergunta: Qual mensagem você gostaria de deixar para nós que estamos iniciando nossa vida profissional e queremos ser bem-sucedidos? 
AD: É aquilo de que falei no começo: não tenho o segredo e a chave do sucesso, não tenho nenhuma fórmula mágica para que as pessoas sejam bemsucedidas na vida. Acho que tudo aquilo que falei hoje aqui foi para dizer isto: não tenho a fórmula. Sou determinado, disciplinado, mas não tenho a fórmula para o sucesso nem gosto muito de fazer gracinha e dizer: "Olha, nunca se endivide, trabalhe só com dinheiro próprio." Penso que tudo é circunstancial, existem momentos em que as pessoas têm de decidir, aceitar riscos na vida e alavancar; se a causa for boa, se o caminho for bom, se o caminho for importante... Eu já fiz isso e deu certo, mas de repente pode não dar, quer dizer, são coisas com que as pessoas precisam aprender a conviver na vida, seguindo seu caminho e enfrentando as dificuldades que forem aparecendo.

Pergunta: Sou funcionário da Compre Bem, em Atibaia, e estudo aqui no curso de Comércio Exterior. Gostaria que o senhor comentasse sobre a ajuda que sua companhia tem dado ao comércio exterior brasileiro e se pretende estender a organização para outros países como fez em Portugal?

AD: Faça seu curso de Comércio Exterior e faça bem feito. Procure conhecer o Marcelo Ubriaco, diretor de nossa trading que se dedica ao comércio exterior, que compra muita mercadoria fora e também exporta mercadoria brasileira, principalmente para os nossos sócios. Espero que você faça bem o seu curso de comércio exterior e seja feliz trabalhando conosco.
Pergunta: Gostaria de saber quais foram os erros que você julga ter cometido e o que aprendeu com isso, especialmente naquela etapa de sua vida que diz ter deixado de ser arrogante e prepotente.

AD: Entendi sua pergunta e gostei muito. Tem uma frase que ouvi do ministro Palocci, um cidadão pelo qual tenho o maior respeito e admiração, embora não seja meu amigo, pois o conheci agora quando estava na reta final da campanha do Lula, portanto sou totalmente insuspeito para falar dele. Tenho enorme admiração por ele, repito, uma pessoa que tem formação em Medicina e está fazendo um trabalho excepcional no campo econômico. Ele me dizia o seguinte: "Só quero cometer nesta vida erros novos, não erros velhos." Acho que isso é sabedoria! Se eu errar novamente, que seja por coisas que eu desconheça, pois o principal é a intenção de acertar. Você precisa ter convicção e vontade muito grande de fazer as coisas certas e acertar. Agora, os meus maiores erros você já apontou: a prepotência e a arrogância. Quando digo que o seqüestro que sofri foi um pouco por minha culpa, é porque eu era tão arrogante e prepotente que não admiti. E quando me vi lá embaixo, naquele buraco, tive raiva de mim: "Como me deixei seqüestrar? Como deixei esses caras me pegarem?". Na verdade, não estava com raiva dos caras, mas de mim, de minha arrogância e prepotência, do ódio por temer por minha vida. Eu achava que tinha de ser um homem de extremos - amar com toda a força e odiar com mais força ainda. O período que passei a visitar Portugal seguidamente foi um terror; era um negócio sombrio, você não tinha ali as pessoas que conhecia, restava ódio àquelas pessoas que estavam tomando a companhia. A coragem nunca me faltou. Eu ia à companhia e encontrava aquele 
clima hostil, aquela gente; tinha um ódio que, se pudesse, matava todos. Hoje percebo que isso não está com nada, o ódio normalmente faz muito mais mal a quem odeia do que a quem é odiado. Por isso, espero que Deus sempre ilumine o meu caminho para que nunca mais cometa os mesmos erros. É tão legal ter humildade e eu me sinto tão bem com ela, que é autêntica, latente em mim, está dentro do peito - acho que isso é o importan- te. Hoje avalio que os erros que cometi deveriam ter sido evitados; foram inúmeros, pois sou um sujeito absolutamente normal, mas os principais eu acredito que tenham sido a postura de vida e a própria briga de familia. Se eu fosse um cara mais conciliador será que não teria conseguido uma história diferente? Não sei, nunca foi tentado. É isso, obrigado pela pergunta. 
20 